\title{
CUADRO AMBIENTAL DE LA COCHA CAROCURAHUAITE Y POSIBILIDADES DE EXPLOTACION DEL CAMARON DE RIO (Macrobrachium amazonicum)
}

MONTREUIL FRIAS VLCTOR H. $\left(^{*}\right)$

MACO GARCIA JOSE (*)

TELLO MARTIN SALVADÓR $\left(^{*}\right)$

ISMIÑO ORBE ROSA $\left({ }^{*}\right)$

SANCHEZ RIVEYRO HOMERO $\left(^{*}\right)$

\section{INTRODUCCION}

L a cocha Carocurahuaite está situada en la margen derecha del río U cayali, aguas arriba de R equena; Geográficamente, se ubica entre los 50 09 y 50 13' de latitud Sur; y 730 04' de longitud Oeste. Este cuerpo de agua que, por su origen y forma, se le denomina desde el punto de vista fisiográfico como meandro abandonado, está formado por una "cocha principal" de gran tamaño, en forma de herradura, con una isla dentro de ella, .que ocupa aproximadamente una cuarta parte de su superficie; una " cocha secundaria, más pequeña, que se asemeja a una media luna, y dos caños de conexión, uno pequeño, entre la cocha principal y la secundaria y otro más grande, entre la cocha secundaria y el río U cayali.

Durante el período hidrográfico de avenidas, entre los meses de noviembre y mayo, el río U cayali invade, a través de varios puntos, este cuerpo de agua, proporcionándole nutrientes y oxigenando sus aguas. Este fenómeno de enriquecimiento da a las aguas de la cocha Carocurahuaite especiales características físicas, químicas y biológicas que permiten una elevada productividad. Esta productividad excepcional se refleja en la gran magnitud de recursos pesqueros que alberga, destacando particularmente el camarón de río, como una especie de buena potencialidad.

En esta investigación se presentan informaciones físicas, químicas y biológicas de las aguas de la cocha Carocurahuite y algunas características de la pesquería, así como métodos de conservación y comercialización del camarón de río, 
esperando que todas estas informaciones sirvan como una base para estudios más profundos, tendientes a una óptima utilización de los recursos hídricos e hidrobiológicos de la región.

\section{MATERIAL Y METODOS}

1. Parámetros morfométricos de la cocha Carocurahuatia

Se determinó en base a aerofotografías verticales, en blanco y negro, a la escala de 1: 40,000, elaboradas por el Servicio Aerofotográfico Nacional (SAN) y utilizando un planímetro, escalímetro y curvímetro.

1.1. Longitud máxima (LM ): Línea que une los puntos más lejanos y extremos de un cuerpo de agua lénticos; cuando la 'cocha tiene forma de herradura o semilunar, la longitud máxima puede ser una línea curva, aunque ella cruce tierra firme, siempre que sea una isla (Fukushima) et al 1980. Esta definición se adapta perfectamente a la situación del área de estudio.

1.2. Longitud máxima efectiva ( $L M E$ ): Línea que une los puntos más extremos de un cuerpo de agua y en la que el desplazamiento de un flujo de agua uo es interrumpido por alguna porción de tierra firme (Fukushima et al 1980).

1.3. Anchura máxima $(A M)$ : Línea que une los puntos extremos de un cuerpo de agua, pero en sentido transversal y perpendicular al eje de la longitud maxima (Fukushima et al 1980).

1.4. A nchura máxima efectiva (AME): Es la medida de la distancia que existe entre los puntos extremos transversales de un cuerpo de agua y que es perpendicular al eje de la longitud máxima efectiva. Esta línea no debe ser interrumpida por ningún obstáculo de tierra firme (Fukushima et al 1980).

1.5. Anchura media $(A X)$ : Es la relación entre el área del cuerpo de agua y su longitud máxima: 


$$
A X=\frac{A}{L M}
$$

1.6. Profundidad máxima (PMx): Es la máxima profundidad registrada en los sondajes (Fukushima et al 1980). En este caso se considerará este parámetro solo como una aproximación, pues se origina de un único sondaje en el centro del cuerpo de agua.

1.7. Profundidad media (PX): Es la relación entre el volumen (V) y el área (A):

$$
P x=\frac{V}{A}
$$

1.8. Longitud de la línea de orilla ( $L O)$ : Corresponde a la medida del perímetro del cuerpo de agua (Fukushima et al 1980).

1.9. Desarrollo de la línea de orilla (DO): Expresa el grado de irregularidad de la línea 0 el grado de aproximación a la circunferencia. El índice más bajo que se puede encontrar es 1.0 (F ukusbima et al 1980) y el cálculo se hace a través de la siguiente fórmula:

$$
D O=\quad \begin{aligned}
& L O \\
& \hdashline-\cdot-
\end{aligned}
$$

1.10. Area (A): Es la determinación de la extensión superficial del espejo de agua.

1.11. Volumen (V): Se calcula estrato por estrato (Fukushima et al 1980); pero, en nuestro caso, debido a que se tuvo solo un dato de profundidad, se considerará el volumen calculado como un indicativo que debe corregirse cuando se tenga mayor información batimétrica de este cuerpo de agua.

1.12. Desarrollo del volumen (DV): Este parámetro expresa el grado de cercamiento del lecho a la forma cónica. Cuando un cuerpo de agua tiene un volumen igual al de la forma cónica, el DV. Es igual a 1.0; citando el volumen es mayor que su cono hipotético, el índice será mayor que 1.0 y si el volumen es menor que su cono hipotético el valor será menor que 1.0 (Fukushima et al 1980). 
Para calcular el DV, hay que recordar que el volumen de un cono es el tercio del producto de su área basal por la altura, donde el primero es sustituído por el área superficial (A) y el segundo por la profundidad máxima (PM X). Desde que el volumen de un lago es igual al producto del área por la profundidad media (PX), la relación del volumen del lago con el volumen de su cono teórico será el que se expresa en la fórmula siguiente (F ukushima et al 1980):

$$
D v=\frac{A(P X)}{1 / 3 A(P M x)}
$$

Simplificado:

$$
D V=3\left(\begin{array}{c}
P X \\
-9 M x
\end{array}\right.
$$

\section{Parámetros físico-químicos de la cocha Carocurahuaite}

Durante 24 horas y en intervalos de 6 horas $(06,00$ y 12,00, 18,00 y 24,00 hr.) se hicieron mediciones de los siguientes parámetros físico-químicos: Temperatura del aire y del agua; color aparente; transparencia; turbidez; conductividad; oxígeno disuelto; anhidrido carbónico; alcalinidad total; dureza total; dureza de calcio; dureza de magnesio; nitrato; nitrito; amoniaco; sulfato; ortofosfato, fósforo, cloruros y pH.

Para la toma de la temperatura del aire y del agua se utilizó el termistor de un oxímetro YSI modelo 57. El color aparente se determinó visualmente y la transparencia con la ayuda de un disco secchi.

La turbidez, anhidrido carbónico, alcalinidad total, dureza, nitrato, nitrito, amoníaco, sulfato, ortofosfato y cloruros, se determinaron con un espectrofotómetro M ini 20 Bausch and Lomb y los spectrokits correspondientes a cada parámetro.

El oxígeno disuelto se midió con un oxímetro Y SI modelo 57, equipado con una sonda cat R - 5521, con membrana estandard $0.20 \mathrm{mg} / 1$. y un cable de 15 metros de longitud. 
La conductividad se conoció con la ayuda de un conductivímetro Y S 1 modelo 33, con sensor y cable de 15 metros; y el $\mathrm{pH}$. con un $\mathrm{pH}$ metro digital Cole Palmer.

\section{Plancton}

La recolección del plancton se efectuó por filtración, utilizando redes standar con 20 micras de abertura de malla. Se filtraron 200 litros de agua y la muestra se recogió en frascos de $100 \mathrm{ml}$. de capacidad, agregándole $1.5 \mathrm{ml}$. de formol al $40 \%$ para su preservación. Esta muestra fue analizada en el laboratorio, cualitativa y cuantitativamente, tanto para fitoplancton como zooplancton.

Para el análisis cualitativo del fitoplancton, la muestra se homogenizó por agitación y con un gotero se depositó una gota en una lámina portaobjeto; esta muestra se colocó para su observación, en el campo de un objetivo 40X de un microscopio compuesto L eitiz L aborlux $\mathrm{K}$ con cámara lúcida incorporada. Las diferentes especies que fueron apareciendo se identificaron rápidamente; para aquellas más comunes y las especies poco frecuentes, cuya identificación no era posible en el momento, se les dibujó sus características más sobresalientes para que sirvieran de base en su posterior identificación.

Para el análisis cuantitativo del fitoplancton se centrifugó la muestra de $100 \mathrm{ml}$. durante dos (2) minutos, a 3,000 r.p.m. y se concentró a $10 \mathrm{ml}$. Por agitación se homogenizó la muestra y con un gotero se cargó dos (2) retículos de una cámara de N eubauer, contabilizando todos los organismos, según la especie. Para efecto de los cálculos se contabilizaron los organismos de diez (10) recuadros y se utilizó el factor respectivo para referirlo a organismo por litro.

Para el análisis cualitativo de zooplancton se procedió con la misma metodología descrita para el fitoplancton. El análisis cuantitativo varió solamente en la utilización de una cámara tipo Sedgwick - Rafter de 1 c.c. de capacidad.

\section{Captura de especímenes de camarón}

Los especímenes de camarón utilizados para este estudio fueron capturados mediante tres métodos de captura. Primero, de acuerdo a la forma tradicional, empleando una canastilla o cesta hecha de fibra de punga (Bombax manguba) o de tamshi (Heteropsis sp.). La canastilla o cesta tiene la forma de un cono truncado de aproximadamente $70 \mathrm{~cm}$. de largo, $25.30 \mathrm{~cm}$. de diámetro en el borde superior y 12 $15 \mathrm{~cm}$. en el borde inferior (Gonzáles, 1975), (Fig. 3). 
Estas cestas son amarradas a varillas de madera de aproximadamente $1.50 \mathrm{~m}$. que se fijan en el fondo del cuerpo de agua, cerca de la orilla, quedando la canastilla a una profundidad de $3-40 \mathrm{~cm}$. En el fondo de la cesta se coloca, como carnada, restos 0 vísceras de peces, o yucas en proceso de fermentación y, a veces, cueros de cerdo cocido con sal (Gonzáles 1975). Cada 465 horas las cestas son revisadas, recogiendo los camarones que se encuentran en cada una de ellas.

Otro aparejo de pesca utilizado para la captura de camarón es a pusahua (Fig. $4 \mathrm{~b})$, que es una red tipo cuchara de malla menuda $(2 \mathrm{~mm}$.) de material sintético, con un aro metálico de $75-90 \mathrm{~cm}$. de diámetro y con un mando de 1.20

- $1.60 \mathrm{~m}$. de longitud; se opera desde la orilla, pie a tierra, o desde una embarcación, sumergiendo el aparejo con habilidad y rapidez en la zona donde se encuentran las camarones para embolsarlos con un rápido tirón y sacarlos fuera del agua (Hanek, 1982).

El tercer aparejo fue una red de malla fina $(2 \mathrm{~mm}$.) dc $6 \mathrm{~m}$. de largo y 2 de ancho, con la cual se preparó un artefacto de captura, como en la Fig. 4a, utilizando como carnada pedazos de peces y vísceras de los mismos (H inophthal mus edentatus); después de aproximadamente una hora se pudo recoger una captura de por lo menos tres kilogramos de camarones en peso vivo.

\section{Análisis de los especímenes capturados}

Los especímenes capturados (133) fueron conservados en alcohol para su posterior análisis en laboratorio. Diez especímenes fueron enviados al Dr. A ntenor Guerra de la Universidad Nacional de Trujillo, para su identificación respectiva. A simismo, se contó como una guía para la ubicación taxonómica de la especie, el trabajo de tesis de la Blga. Rosa Gonzáles (1975).

La longitud de cada espécimen se midió con un vernier, desde el borde posterior de la órbita del ojo hasta el extremo del Telson, y el peso con una balanza electrónica Sauter, con aproximación a $0.1 \mathrm{mg}$. Deberá tenerse presente que estas mediciones fueron hechas en especímenes conservados en alcohol.

Se realizaron, también, algunas observaciones biológicas, como sexado, análisis del contenido estomacal y, asimismo, se contábilizaron los huevos de las únicas cuatro hembras ovigeras que pudieron capturarse. 


\section{Métodos de conservación}

Se hicieron anotaciones sobre el método de conservación tradicional que practican los pobladores de la ribera. A unque no fue posible determinar el factor de conservación de camarón fresco a camarón seco, se logró obtener la producción de "colitas de un kilogramo de camarón seco. Finalmente, se tomó conocimiento de algunos aspectos de comercialización del producto final.

\section{RESULTADOS}

1. Parámetros morfométricos de la cocha Carocurahuaite.

a) Cocha princinal.

* Longitud máxima (L M )

$19,440 \mathrm{~m}$.

* L ongitud máxima efectiva (L M E)

$5,620 \mathrm{~m}$

* A nchura máxima (AM)

$2,360 \mathrm{~m}$

* A nchura máxima efectiva (AME)

$800 \mathrm{~m}$.

* A nchura media (AX)

$772 \mathrm{~m}$.

* Profundidad máxima (PMX)

$14 \mathrm{~m}$.

* Profundidad media (Px)

$4.84 \mathrm{~m}$

* L ongitud de la línea de orilla (L O)

$39,904 \mathrm{~m}$.

* Desarrollo de la línea de orilla (D O)

$2.91 \mathrm{~m}$.

* Area

$15^{\prime} 013,333 \mathrm{~m} 2$

* V olumen

$72^{\prime} 674,060 \mathrm{~m} 3$

* Desarrollo del volumen

1.04

\section{b) Cocha secundaria.}

* L ongitud máxima

$3,400 \mathrm{~m}$.

* L ongitud máxima efectiva

$1,760 \mathrm{~m}$

* A nchura máxima

$300 \mathrm{~m}$.

* A nchura máxima efectiva

$300 \mathrm{~m}$

* A nchura media

$259 \mathrm{~m}$.

* L ongitud de la línea de orilla

$6,904 \mathrm{~m}$

* Desarrollo de la línea de orilla

2.07.

* A rea

$882,083 \mathrm{~m}^{2}$ 
c) Caño de conexión entre la cocha princinal y la secundaria.

* Longitud

$960 \mathrm{~m}$.

d) Caño de conexión entre la cocha secundaria y el río Ucayali.

* L ongitud

$4,006 \mathrm{~m}$.

2. Parámetros físico - químicos de la cocha Carocurahuaite.

a) Color aparente del agua: V erde amarillento (Cuadros 1 - 4).

b) Temperatura del agua: En el muestreo de las 06,00 horas la temperatura superficial del agua fue de $28.6^{\circ} \mathrm{C}$, para aumentar hasta 28.70 C a 1 metro de profundidad, para luego disminuir paulatinamente, con el aumento de la profundidad, hasta alcanzar los 26. 2 C a 12 metros (Cuadro №. 1, Fig. 5). A las 12,00 horas, la temperatura superficial del agua estuvo en $30.5^{\circ} \mathrm{C}$., disminuyendo bruscamente hasta $27.5^{\circ} \mathrm{C}$ en los primeros 2.5 metros de profundidad y, a partir de este punto, bajar suavemente a 27.0 $\mathrm{C}$ en los 6.0 metros, para luego hacerse constante en esta temperatura en todo el resto de la columna de agua (Cuadro No . 2, Fig. 6).

A las 18,00 horas, la temperatura superficial del agua fue $30.90 \mathrm{C}$, bajando a 30.8 - $\mathrm{C}$ a Im. de profundidad y disminuyendo hasta $28.1^{\circ}$ C a los 2.5 metros y, a partir de este punto, el agua fue enfriándose suavemente con el aumento de la profundidad, hasta $26.3^{\circ} \mathrm{C}$ en los 12.0 metros (Cuadro $\mathrm{N} 0.3$, Fig. 7). Finalmente, a las 24.00 horas, latemperatura superficial fue $29.30 \mathrm{C}$ en los 4.0 metros y haciéndose Constante en $27.0^{\circ} \mathrm{C}$, a partir de los 5.0 metros (Cuadro №. 4, Fig. 8).

c) Transparencia: La permeabilidad lumínica osciló entre 158 (12.00 horas) y 160 (06,00 horas) centímetros (Cuadros $\mathrm{N} 01$ y 2).

d) Turbidez: La turbidez tuvo un comportamiento similar durante el transcurso del día, a través de la columna de agua; salvo para el muestreo de las 12.00 horas. Se inició con un valor entre 4 (18.00 horas) y 14 FTU (06.00 horas) en la superficie, disminuyendo en el primer metro de profundidad, para aumentar paulatinamente hacia las 
partes más profundas (Cuadros $N$ N. 1, 3 y 4; Fig. 5, 6 y 8). En el muestreo de las 12,00 horas, se inició con un valor mínimo (0-FTU) en la superficie, incrementándose con el aumento de la profundidad (Cuadros No. 2; Fig. 6).

e) Conductividad: A unque la tendencia general de la conductividad fue casi siempre aumentar con la profundidad, ésta tendencia no siguió un modelo regular, mostrando más bien el graficado de sus valores (Cuadros No 1 - 4) una línea quebrada (Fig. 5 - 8).

f) Oxígeno disuelto: En los cuatro muestreos efectuados durante el día, los valores del oxígeno superficial fueron los más altos, oscilando entre 8 y 9.8 ppm (Cuadro No. 1 - 4; Fig. 5 - 8). Estas concentraciones se mantuvieron altas hasta la profundidad de 1.0 metros, luego disminuyeron bruscamente hasta el nivel de concentración de 0.1 ppm., en los estratos inferiores.

g) Anhidrido carbónico: Las concentraciones de anhidrido carbónico fueron inversamente proporcionales. a las del oxígeno, con los niveles más bajos ( $3-6$ ppm.) en el estrato superficial y los más elevados ( 9 - 11 ppm.) en las zonas más profundas de la columna de agua (Cuadros $N \cong 1$ - 4; Figs. 5 - 8).

h) Los Nutrientes: Tuvieron un comportamiento irregular a través de la columna de agua (Cuadros № 1 - 4). Toda esta información debe considerarse como referente al ciclo hidrológico de media vaciante (junio), en que los niveles estuvieron entre 132 a 142 m.s.n.m. (Fig. 9).

3. Plancton
a) Fitoplancton.

* A nálisis cualitativo. Se encontraron 11 géneros con 14 especies, distribuídas de la siguiente manera:

* Euglenophyta

* Chrysophyta

* Chlorophyta

* Cyanophyta
1 género

2 géneros

6 géneros

2 géneros 2especies

2especies

7especies

3especies

L os fitoplanctontes identificados fueron los siguientes: 


\section{División E uglenophyta.}

Familia Euglenaceae

Género Trachelomona

Trachelomona volvocina

Trachelomona armata

\section{División Chrysophyta.}

Familia $\mathrm{N}$ aviculaceae

Género Navícula

Navícula sp.

Familia Coscinodiscaceae

Género Coscinodiscus

Coscinodiscus sp.

\section{División Chlorouhyta.}

Familia V olvocaceae

Género Eudorina

Eudorina elegans

Familila Chlorococacea e

Género Shoederja

Shoederia setigera

Familia Hydrodictyaceae

Género Pediastrum

Pediastrum duplex

Pediastrum simplex 


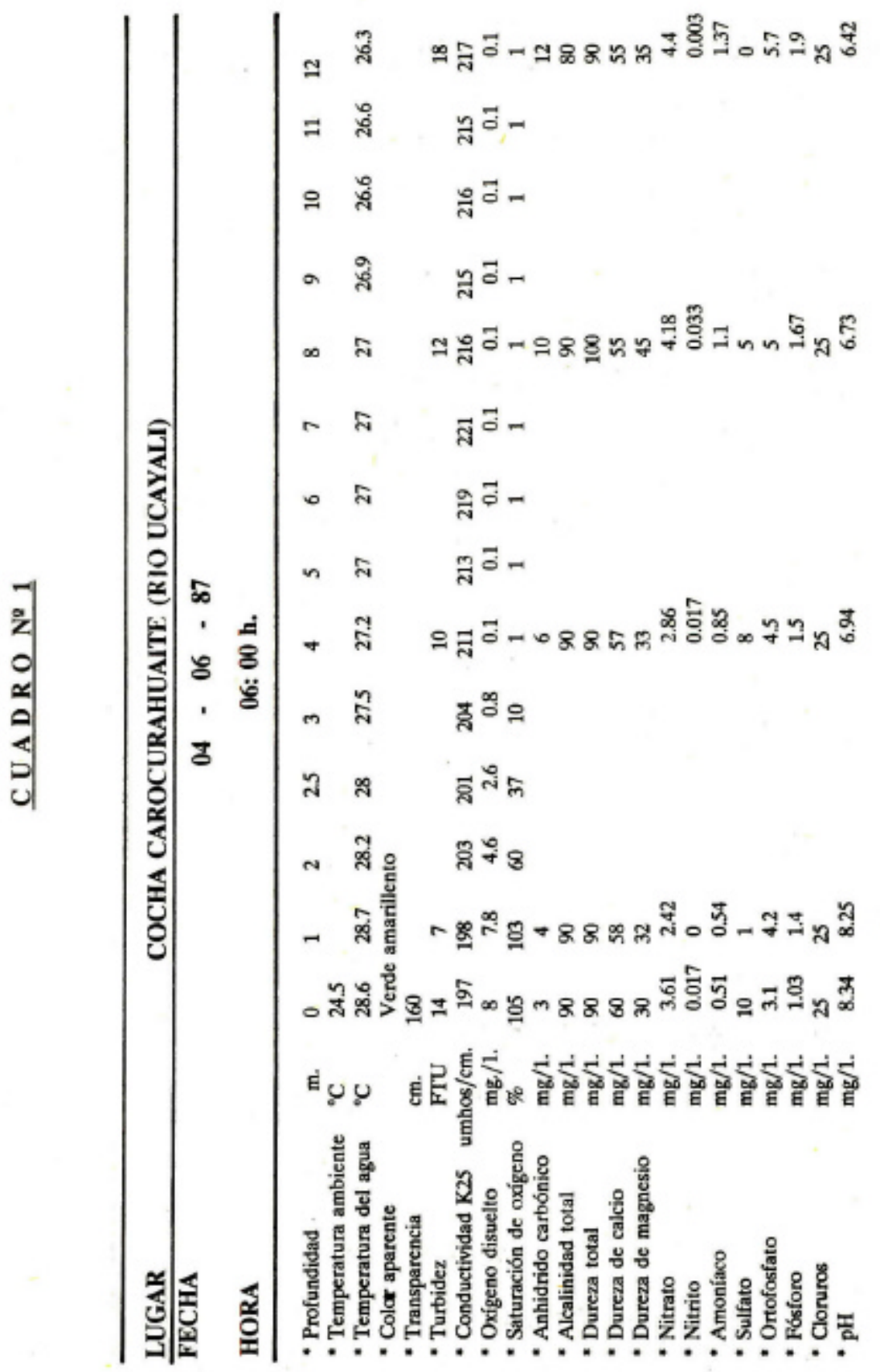




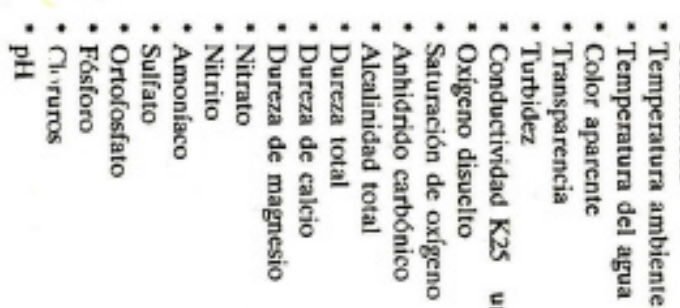

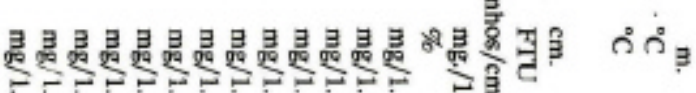

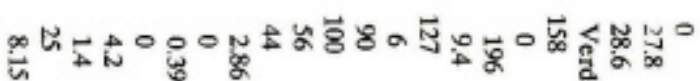

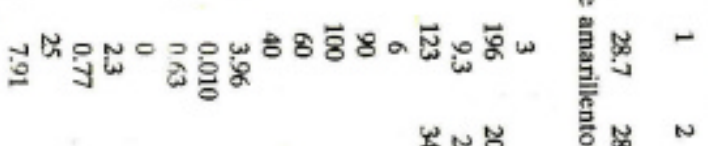
政

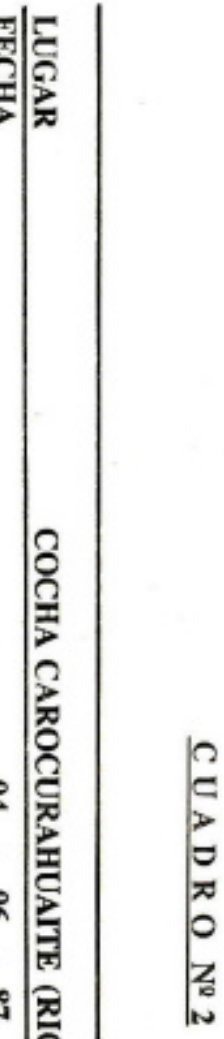

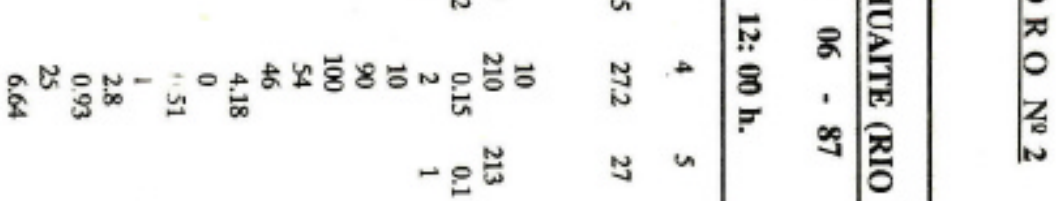

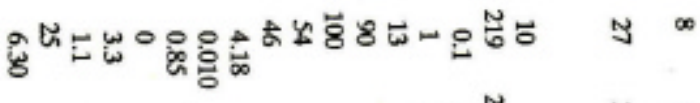

$-\sigma^{2}$
$-\sigma^{2}$
$-\frac{2}{2}$
$-\frac{2}{2}$

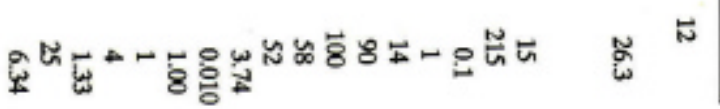




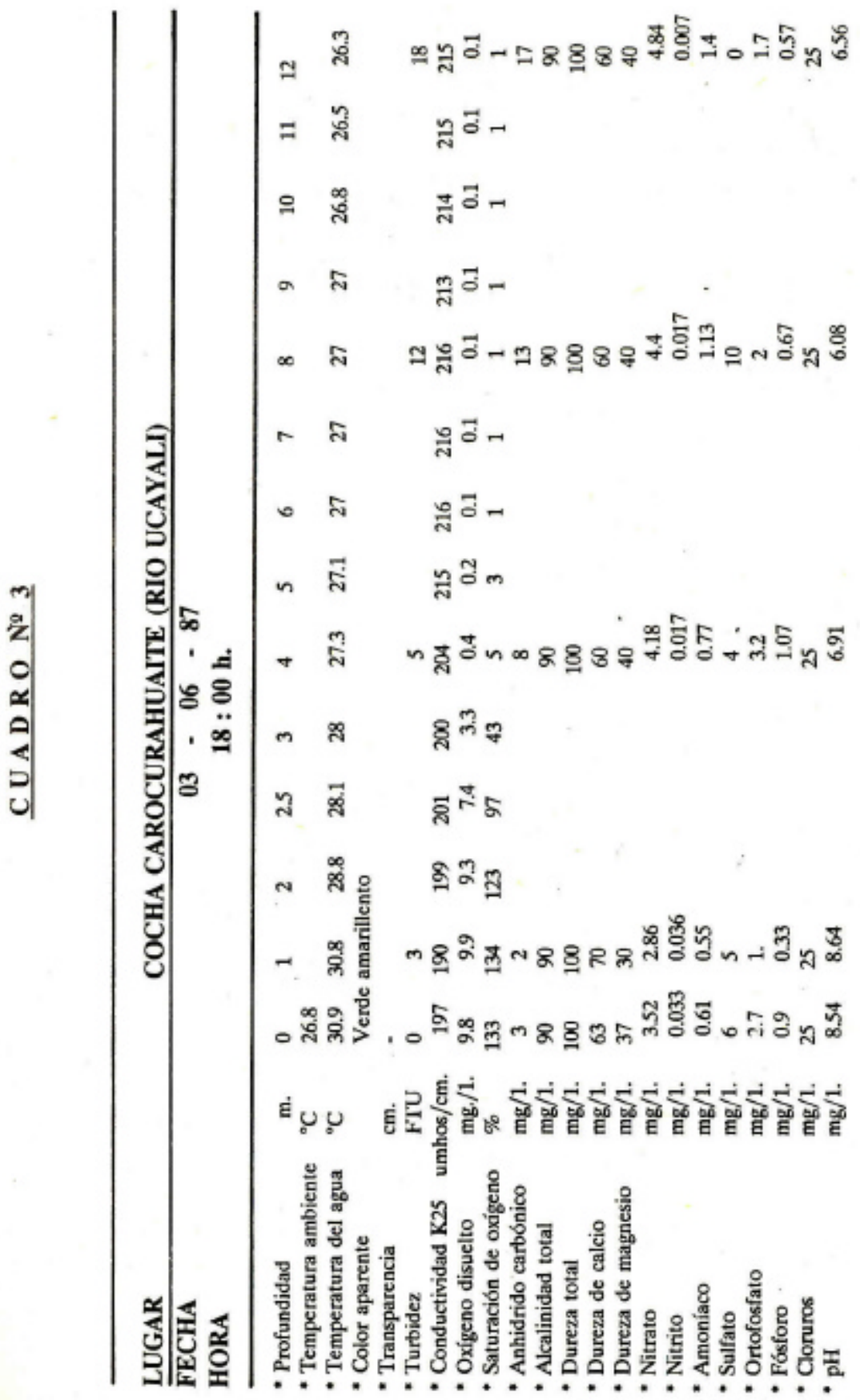




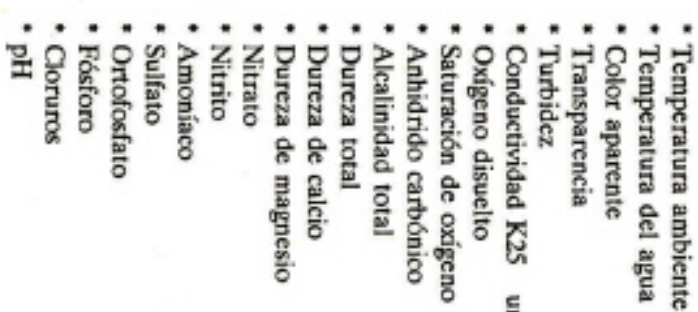

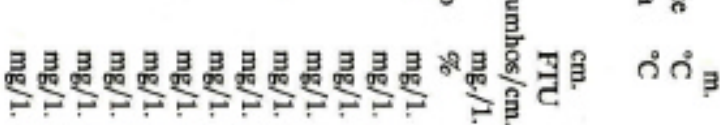

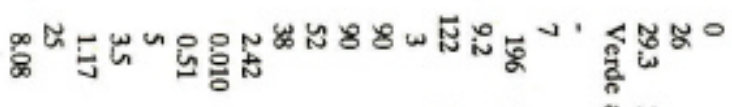

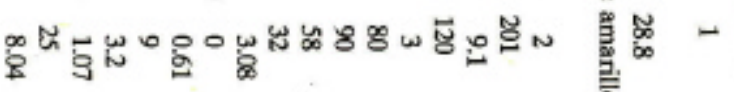

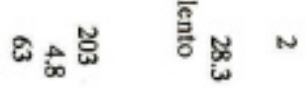
药萬

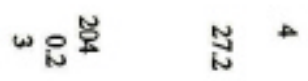

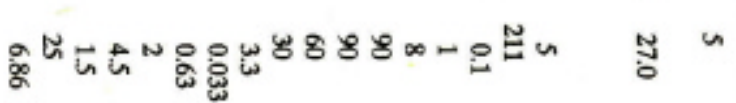

\begin{tabular}{|c|c|}
\hline$-\rho \frac{N}{n}$ & Nid \\
\hline$-\rho \frac{N}{n}$ & ב. \\
\hline$-\rho \frac{N}{2}$ & $N$ \\
\hline
\end{tabular}

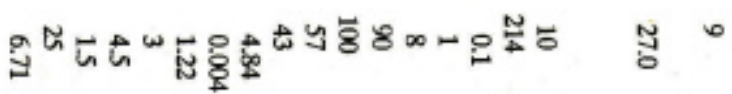
- 윤 분

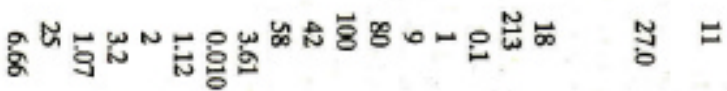
-

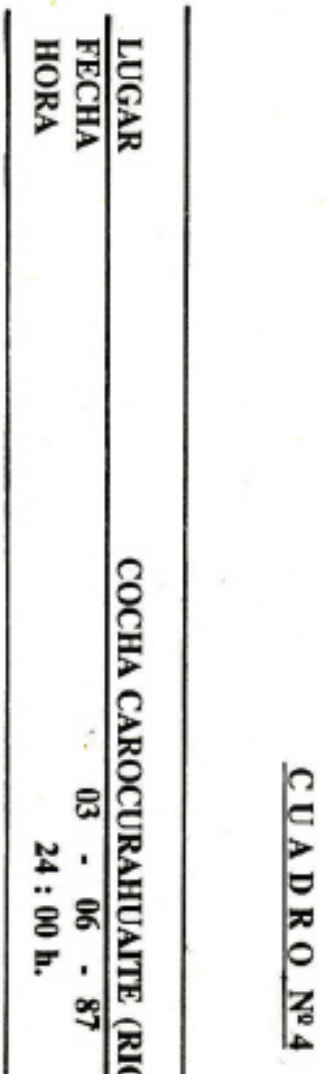


Familia Desmidiaceae

Género Closterium

Closterium gracile

Género Hyalotheca

$\underline{\text { Hyal otheca sissiliens }}$

Familia Coelastraceae

Género Coelastrum

Coelastrum microporum

División Cyanophyta

Familia Chroococaceae

Género M erismopedia

M erismopedia sp.

Familia N ostocaceae

Género A nabaena

A nabaena spiroides

A nabaena $\underline{\text { circinalis }}$

A nálisis cuantitativo: Eudorina elegans (Chlorophyta) fue la especie que se presentó en mayores concentraciones $(290,000$ org. /It.), seguida de Anabaena spiroides (Cyanophyta) con 39,500 org./lt... A continuación, se presenta una lista de las especies más abundantes en las muestras analizadas:

Euglenophyta

Trachelomona volvocina

Trachelomona armata

Chrysophyta

Coscinodiscus sp.

Chlorophyta
$1.500 \mathrm{org} . / \mathrm{tt}$.

500 org./lt

1,000 org./lt

$\underline{1,500 \text { org./lt }}$

1,500 org./lt

324,000 org.//t. 
Eudorina el egans

Shoederia setigera

Pediastrum duplex

Pediastrum simplex

Closterium gracile

Hyal otheca dissiiens

Coelastrum microporum
290,000 org. / It. $16,000 \mathrm{org} . / \mathrm{lt}$.

2,000 org. /lt.

1,000 org./lt.

$500 \mathrm{org} . / \mathrm{lt}$

$1,000 \mathrm{org} . / \mathrm{It}$

$13,500 \mathrm{org} . / \mathrm{tt}$.

$\underline{48,500 \text { org. } / / \mathrm{t} .}$

1,000 org./It.

39,500 org./lt.

8,000 org./It

b) Zooplancton.

- A nálisis cuali-cuantitativo. Dayhnia sp. (Cladócero) - fue la más abundante $\left(2,100 \mathrm{org} . / \mathrm{m}^{3}\right)$, seguida de Nauplios $\left(1,600 \mathrm{org} . / \mathrm{m}^{3}\right)$ y Ciclopoideos $(1,600$ org. $\left./ \mathrm{m}^{3}\right)$. U na lista de las zooplanctontes encontrados en las muestras analizadas se conforma de la siguiente manera:

Cladóceros:

Daphnia sp.

Daphnia dubia

Daphnia ambigua

Ceriodaphnia sp.

Alona sp.

Alonella sp.

Chydorus sp.
$3,500 \mathrm{org} \cdot / \mathrm{m}^{3}$

2,100

400

100

400

300

100

100
Copépodos

Cyclopoideos

Calanoideos
$3.000 \mathrm{org} / \mathrm{m}^{3}$

1,600

1,400

Rotíferos

$\underline{1,000 \mathrm{org} / . \mathrm{m}^{3}}$ 
Polyarthra sp.

Fiinia SP.

200

Testudinella sp.

500

N emátodes

$600 \mathrm{org} . / \mathrm{m}^{3}$

$N$ auplios

$\underline{1,600 \mathrm{org} . / \mathrm{m}^{3}}$

Total de org. $/ \mathrm{m}^{3}$

9,700

\section{A nálisis de los especímenes capturados:}

\subsection{Identidad.}

La posición sistemática (taxonomía) de la especie es la siguiente (Gonzáles, 1975).

Reino

Sub-reino

Phyllum

Sub-phyllum

Clase

Sub-clase

Orden

Sub-orden

Familia

Género

Especie
A nimal

M etazoa

Artrópoda

Invertebrata

Crustácea

M al acostraca

Decápoda

Natantia

Palaenonidae

M acrobrachium

M acrobrachium amazonicum (Heller).

4.2 Nomenclatura y sinonimia (Gonzáles. 1975).

De acuerdo a Holthius (1952) se tiene la siguiente nomenclatura de la especie.

- Nombre científico : $\quad$ M acrobrachiunt amazonicum (Heller).

- Nombre vulgar : Camarón.

Y ucra o Puca-Y ucra, en el departamento de San M artín.

L as sinónimas las da el mismo Holthius (1952). 
- Palaemon amazonicus Heller, 1862, 8 .B. A kad Wiss. Wien vol. 45, pT. 1, p. 418, pl. 2, fig. 45.

- Palaemon ensiculus. Smith, 1869, Trans Conn. Acad. Arts. Sci. , vol, 2, p.p. 26, 40, pl. 1, Fig. 2.

- Palaemon lamarrei De M an, 1879. N otes Leyden. M us., vol. 1, p. 166.

- Paláemon amazonicus Ortmann, 1897. Rey. M us. Paul., vol. 2, p. 204.

- M acrobrachium amazonicus Schmitt, 1936, Zool. Jb. Syst. vol. 67 p. 373.

- M acrobrachium amazonicus Holthius, 1950 a., Siboga Exped M on. 39a 9, p. 12; Holthius, 1950 b, Zool. Meded., vol. 31, p. 29.

\section{Descripción del G énero M acrobrachium. Bate (1868) (G onzáles 1975).}

Rostrum bien desarrollado, comprimido y dentado, caparazón provisto - de espina antenal, hepática y branquistegal. Telson con dos pares de espinas posteriores, uiandibulas con los tres palpos unidos, Los expodos están entre los maxilípedos, las pleurobranquias sobre el tercer maxilipedo y todos los periópodos; los tres últimos pares de patas con las uñas simples. Los propodios del quinto par de patas poseen numerosas filas de setas transversales en la parte distal del margen posterior, el primer pleopodo del macho sin apéndices internos (Fig. 10).

\subsection{Características morfoniétricas de los especímenes capturados.}

La longitud promedio (desde el borde posterior de la órbita hasta el extremo del telson) fue de $4.1 . \mathrm{cm}$. (Cuadro $\mathrm{N} N$ 5) y el peso promedio $0.85 \mathrm{~g}$. U na regresión entre la longitud y el peso dio como resultado la siguiente ecuación (Fig. 12).

$$
Y=-1.221354+0.504635 X
$$

con $r=0.93$ 


\section{CUADRO No5}

\section{DISTRIBUCION DE FRECUENCIAS DE LONGITUD, PORCENTAJES, RANGO Y LONGITUD PROMEDIO DE LOS ESPECIMENES UTILIZADOS.}

\begin{tabular}{ccc}
\hline LONGITUD & FRECUENCIA & $\%$ \\
\hline $1.41-1.80$ & 1 & 0.7 \\
$1.81-2.20$ & - & - \\
$2.21-2.60$ & 6 & 4.5 \\
$2.61-3.00$ & 7 & 5.3 \\
$3.01-3.40$ & 11 & 8.3 \\
$3.41-3.80$ & 30 & 25.6 \\
$3.81-4.20$ & 23 & 17.3 \\
$4.21-4.60$ & 11 & 5.3 \\
$4.61-5.00$ & 22 & 16.5 \\
$5.01-5.40$ & 13 & 9.8 \\
$5.41-5.80$ & 8 & 6.0 \\
$5.81-6.20$ & 1 & 0.7 \\
\hline- & & \\
$\mathrm{L}=4.10 \pm 0.15 \mathrm{~cm}$. & $\mathrm{n}=133$ & rango $=$ \\
\hline
\end{tabular}

En el margen superior del rostrum se contabilizó de 7 a 12 dientes, con un promedio de 9 , y en el margen inferior de 6 a 9 dientes, con un promedio de 7.

El sexado de 103 especímenes dio como resultado que el 66\% estuvieron - constituidos por hembras y el 34\% por machos, con una relación macho: hembra de 1:2 (Fig. 13).

El conteo total de los huevos de cuatro hembras ovígeras dio un promedio de 1,025 huevos por hembra. Pero, existió una proporcionalidad directa entre el tamaño de los especímenes y el número de huevos que contenían: 


\section{CUADRO № 6}

\begin{tabular}{|c|c|c|c|}
\hline \multicolumn{4}{|c|}{ RELACION NUMERO DE HUEVOS - HEMBRAS } \\
\hline HEMBRAS & LONGITUD & PESO - GR & No DE HUEVOS \\
\hline 1 & 5.0 & 1.66 & 840 \\
\hline 2 & 5.0 & 1.60 & 1,029 \\
\hline 3 & 5.7 & 1.60 & 1,142 \\
\hline 4 & 5.2 & 1.60 & 1,090 \\
\hline
\end{tabular}

EI análisis del contenido de 30 estómagos permitió identificar los siguientes ítems alimenticios.

- Fitoplancton

Shoederia sp.

Navícula sp.

- Zooylancton

Rotíferos : N Notholca sp.

Filinia sp.

Lecane sp.

$\underline{\text { Tardigrados : } \quad \text { Hypsibieus } \mathrm{sp} .}$

Nematodos : $\quad$ Dolichodorus sp.

Pangrolaimus sp.

Chromadora sp.

Trilobius sp.

Diplogaster sp.

Rhabdolainus sp.

Achromadora sp.

A naplectus sp.

- Restos vegetales

- Detritus 


\section{M étodos de conservación:}

Una vez extraídos los camarones de los aparejos de captura, se les deposita en ollas, agregándoles un poco de sal; luego, se coloca la olla en el fuego, manteniéndole así durante unos 20 minutos. Luego de este lapso, los camarones son separados del agua extraída de sus cuerpos, por acción del calor y la sal, esparciéndolos sobre hules tendidos en tierra para exponerlos al sol. Después de dos días de intenso sol, se observa que todo el caparazón está completamente "tostado" y seco; entonces estos camarones secos son vertidos en un saco de yute y se les golpea repetidamente sobre la tierra, a fin de pulverizar los caparazones. Esta mezcla de polvo de caparazones y "colitas" se coloca en vasijas poco profundas, mayormente de plástico, para a través del "venteo" separar las "colltas" del polvo. Se determiné, por este sistema, que un kilogramo de camarones secos produce 400 gramos de "colitas" y 600 gramos de polvo de caparazón.

\section{Comercialización de "colitas" de camarón.}

En cada campaña de aproximadamente 1.5 a 2.0 meses, cada familia puede acumular entre 100 a 200 kilogramos de colitas" de camarón, cuyo precio en el caserío es de 150.00 intis por kilo. La comercialización se hace a compradores que vienen especialmente desde Pucallpa para adquirir este producto, que es procesado en Lima y luego expendido como "camaroncito chino.

\section{DISCUSION}

De acuerdo con la clasificación de Sioli de las aguas amazónicas, los ríos de agua blanca o marrón son cuerpos de agua lóticos, ricos en sólidos suspendidos y pH relativamente alto (pH. 6 - 7), así también la cantidad total de sustancias inorgánicas disueltas, variando la conductividad eléctrica entre 50 y 30 u.s.cm-1. La mayor parte de estos ríos han desarrollado grandes áreas de inundación en sus márgenes (Junk, 1984). Estas áreas son favorecidas por un enriquecimiento cíclico durante el período de aguas altas, en que el río principal desborda sus orillas e invade su zona de inundación. Las concentraciones relativamente altas de los nutrientes minerales presentes en este tipo de aguas ocasiona una alta productividad, tanto en la parte acuática (cuerpos de agua de inundación) como en la terrestre (barriales). 
La cocha Carocurahuaite es un típico cuerpo de aguas de inundación, pues durante la fase hidrológica de aguas altas, el río U cayali la invade a través de varios puntos, proporcionándole nutrientes y oxigenando sus aguas. Durante este período, la dirección de las aguas del caño de conexión con el río corre hacia dentro de la cocha, invirtiéndose el sentido de la corriente durante la vaciante.

El análisis físico-químico de las aguas de la cocha Carocurahuaite confirma las afirmaciones hechas arriba, pues se presentaron conductividades elevadas, siempre superiores a 190 umhos/cm. (Cuadros $\mathrm{N} N 1$ - 4. Fig. 5 - 8); el oxígeno disuelto, superficial también es elevado ( $8-9.8 \mathrm{pm}$.) hasta 1.0 metro de profundidad; ésta situación es explicable por la época en que se realizaron los análisis (media vaciante), debido al período de estancamiento de la circulación de las aguas por la estabilidad del período de aguas altas, durante las cuales el oxígeno que ingresa durante la inundación ha venido sufriendo un gasto en las partes más profundas del lago. Finalmente, un análisis de los elementos que propician una elevada productividad (ortofosfato) en este cuerpo de agua, evidencia que las concentraciones son relativamente mayores, sí las comparamos con otros tipos de aguas (negras), (Cuadros $N$ 1 - 4). Todo esto se ve confirmado por la diversidad de especies de fitoplancton y zooplancton encontrados, así como las concentraciones de los mismos; por ejemplo, 290,000 organismos/litro para Eudorina eleeans; 39,500 organismos/litro para Anabaena, spiroides; y en lo referente al zooplancton 2,100 org. /m3 para Daphnia sp. Y 1,600 org. / m3 para Nauplios y Cyclopoideos.

A pesar de que la identificación de los especímenes de camarón capturados fueron corroborados por uno de los mejores especialistas del país ( $\mathrm{Dr}$. A ntenor Guerra), no se puede descuidar la observación del Dr. Hernán Ortega (comunicación personal), en el sentido de que en Venezuela se está desarrollando una tesis de Doctorado, que tiene como hipótesis que los especímenes que se ha utilizado podrían pertenecer a una especie diferente. Aunque podrá argüirse que son especímenes juveniles de M acrobrachium amazonicum. La presencia de hembras ovígeras obliga a considerar muy seriamente la observación del Dr. Ortega, pero, hasta que no se tenga acceso a los resultados de la tesis indica da, se le seguirá considerando como Macrobrachium amazonicum.

Las "colitas" que se obtienen mediante el procedimiento de conservación .el camarón tieñen un buen valor económico y alimenticio, pero, como se indicó, existe un desperdicio de 600 gramos de polvo de caparazones por cada kilogramo de camarón seco. Según referencias del Blgo. Raúl M ayta (comunicación personal), este polvo de caparazones de camarón podría ser utilizado como un excelente saborizante, incrementando de este modo el valor de la especie como 
recurso económico; por ello, es conveniente tratar de mejorar el sistema tradicional utilizado buscando mejorar la producción, ya que se ha comprobado que, manteniéndolo a la temperatura ambiental, dentro de una bolsa plástica durante tres meses, no sufrió ninguna alteración, ni en su textura ni en su sabor.

Finalmente, debemos relevar la gran importancia que tienen los cuerpos de agua de inundación que, por sus características especiales, podrían posibilitar una excelente explotación pesquera del camarón de río, en base a la cual y mediante un aprovechamiento racional, mejorar la alimentación popular.

\section{BIBLIOCRAFIA}

1. A maya, J. y A. Guerra, 1976. Especies de Camarones de los ríos N orteños del Perú y su Distribución. Ministerio de Pesquería. Dirección General dc Investigación Científica y Tecnológica.

2. Fukushima, M. et al. 1982. M étodos Limnológicos. Tercera Edición. Univ. Nac. de Trujillo.

3. Gonzáles Saavedra, Rosa. 1975. Consideraciones Preliminares en el Estudio del Camarón de Río M acrobrachium amazonicum (Hcller). Tesis. UNAP.

4. Junk, W. J. 1984. Ecology of the varzca, floodplain of amazonian whitewater rivers. In the Amazon Limnology and Landscape Ecology of a M ighty Tropical River and its Basin. 


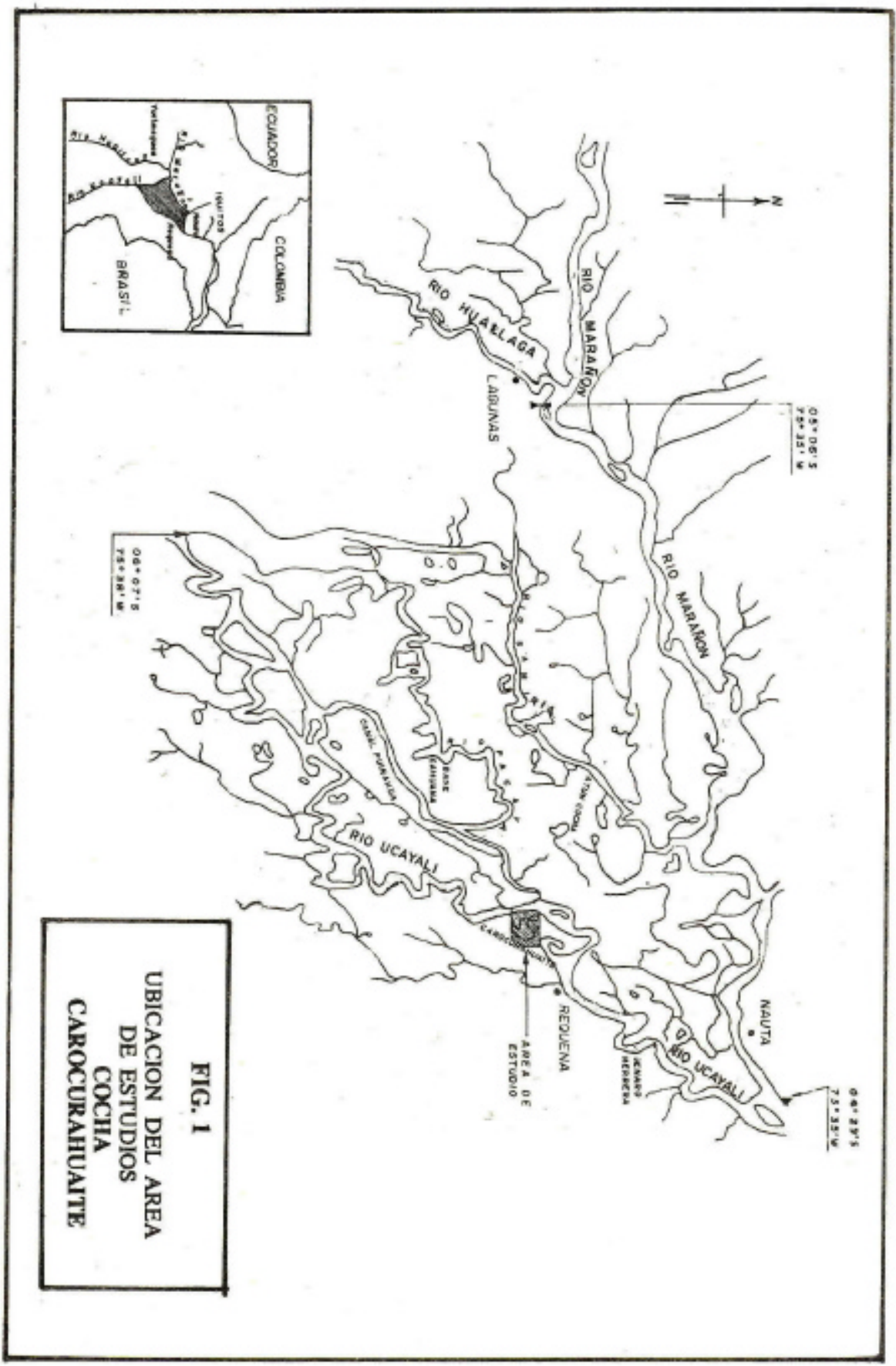




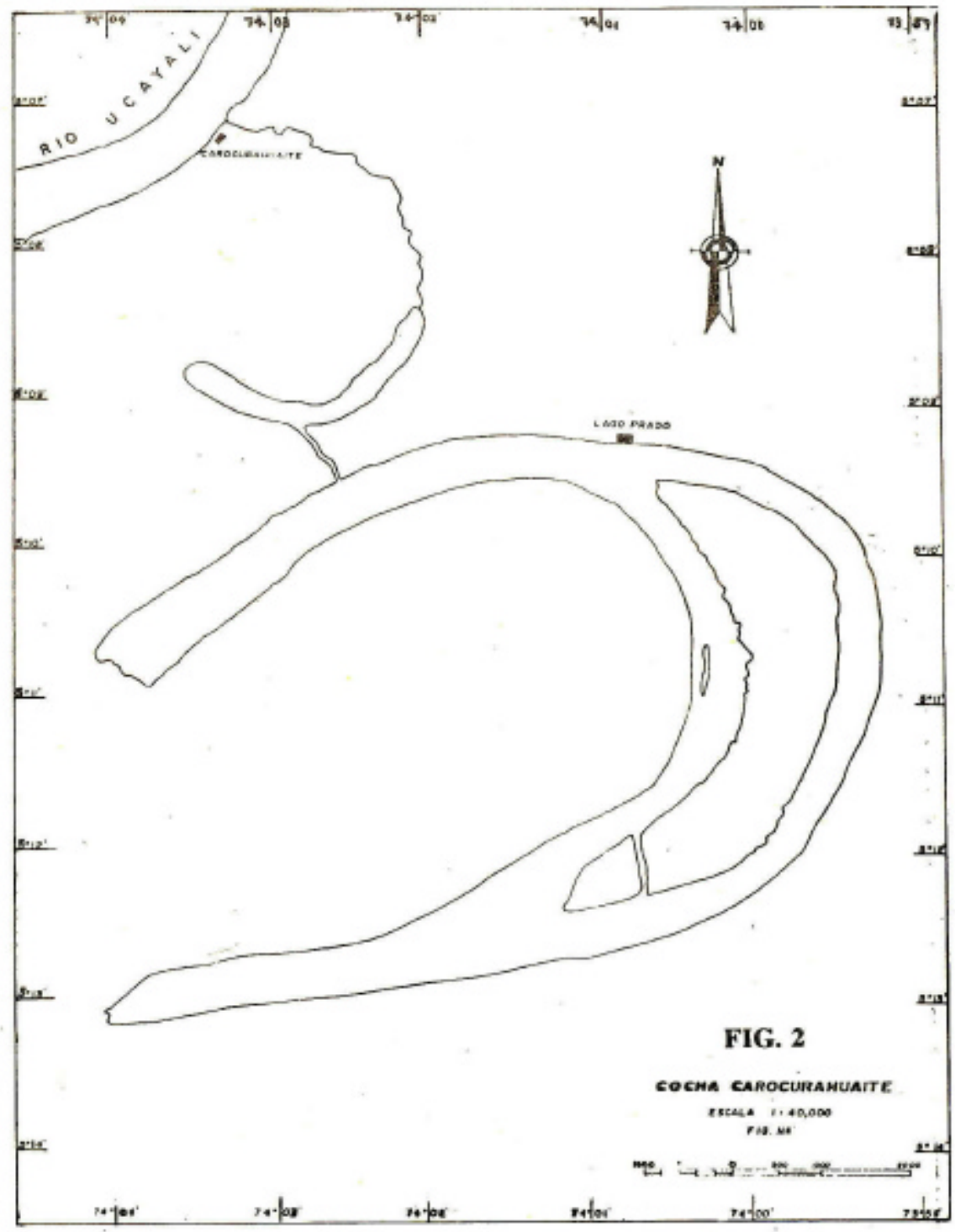


FIG. 5
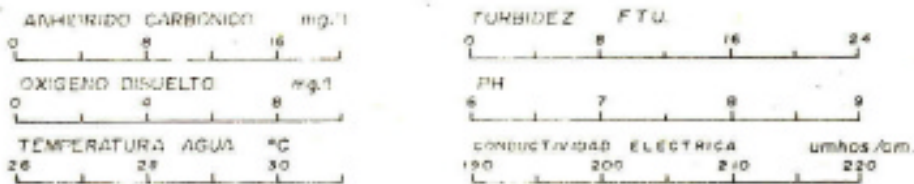

m.
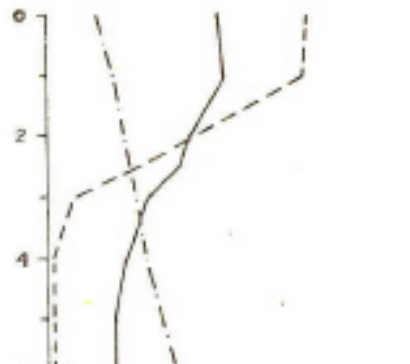

$6-$

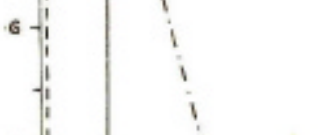

o-

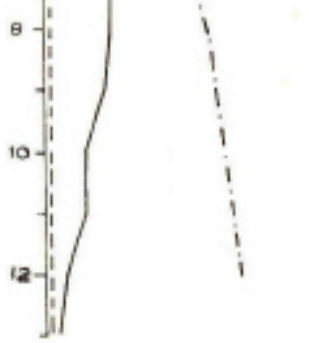

TEMPERATURA AGUA CONDUCTIVIDAD ELECTAICA

- - - OXIGENO OISUELTO

$----P H$

- . - - - ANHICFIDO CARBONICO

-.... TURETEZ

Variaciones de parámetros físicos - químicos en relación a lu profundidad en la cocha Carocurahuaite. Fecha 04-06-87 Hr. 06:00 
FIG. 6
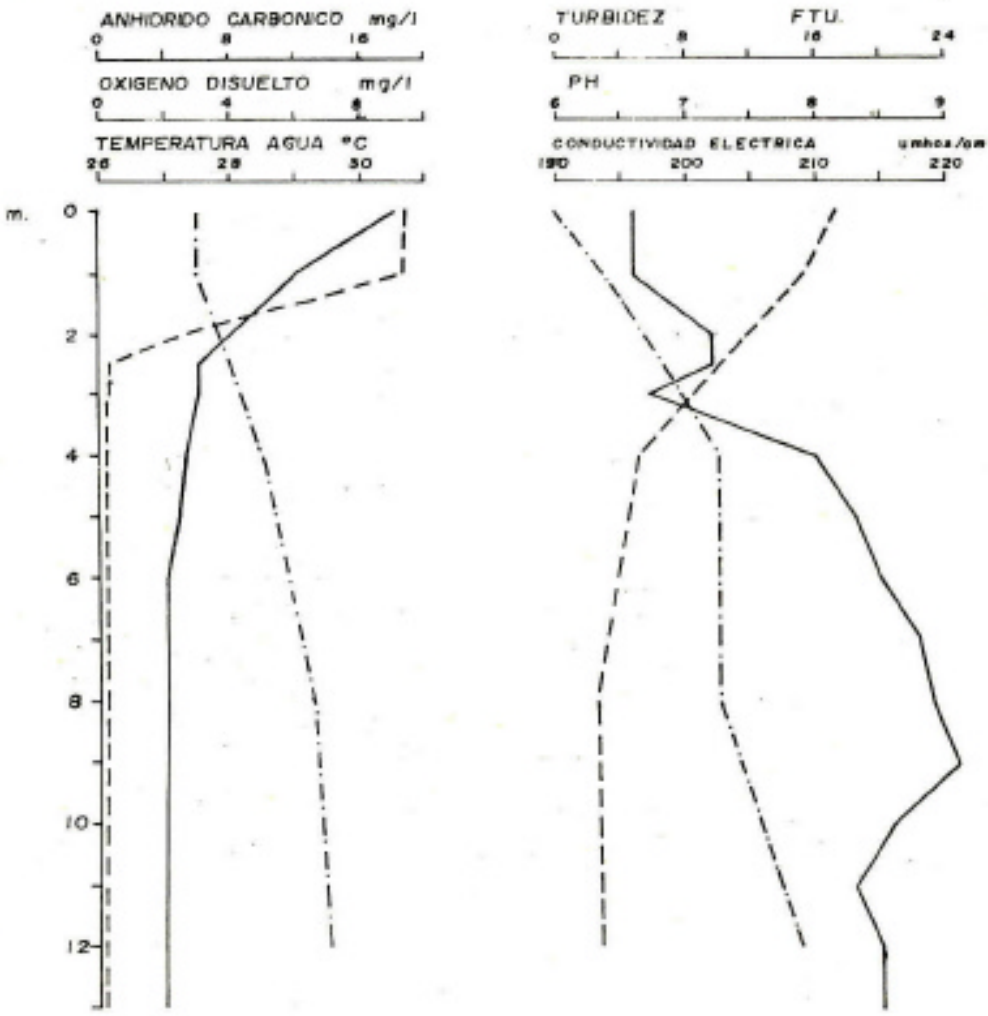

TEMPERATURA AGUA

- - - OXIGENO DISUELTO

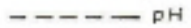

- - - ANHDRIDO CARBOMCO

-.-.-.-. TURBIDEZ

Variaciones de parámetros fisicos - químicos en relación a la profundidad en la cocha Carocurahuaite. Fecha 04-06-87 Hora: 12:00 
FIG. 7
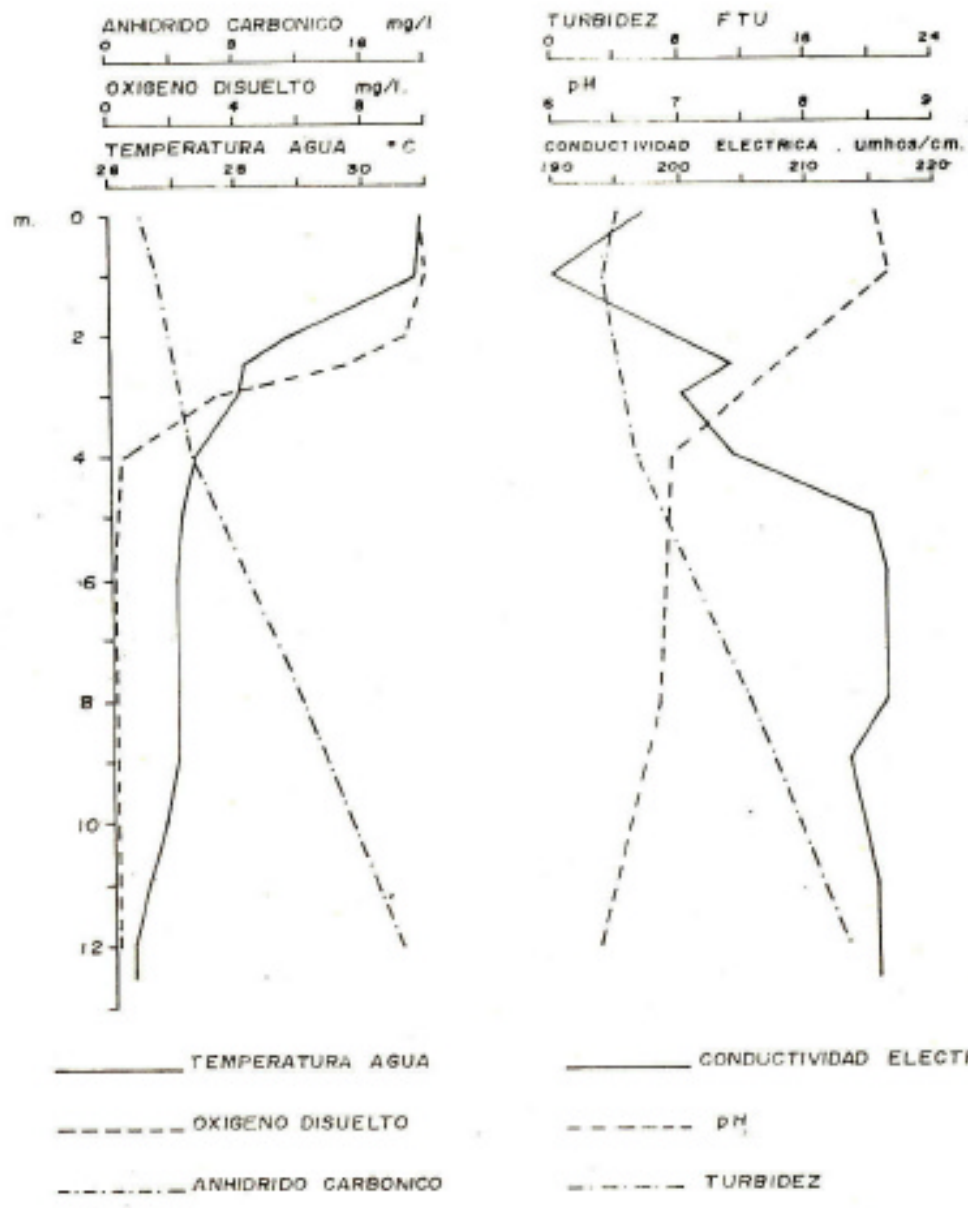

CONDUCTIVIDAD ELECTRICA

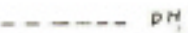

-..... TURGIDEZ

Variaciones de parámetros físicos - químicos en relación a la profundidad en la cocha Carocurahuaite. Fecha 04-06-87. Hora: 18:00 
FIG. 8

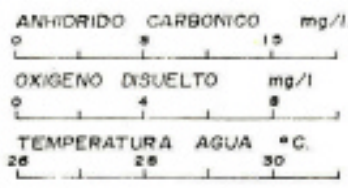

$m$.

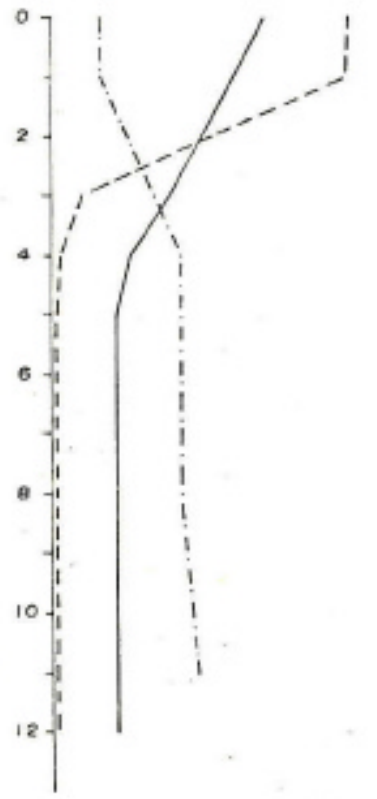

TEMPERATURA AGUA

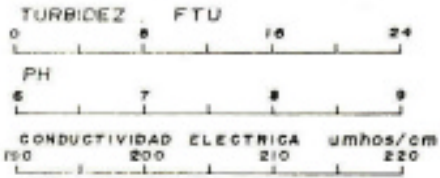

- - - - DXIGFNO DISUELTO

CONOUCTIVIDAD ELECTRICA

PH

-. - . - ANHIDRIDO CARBONICO
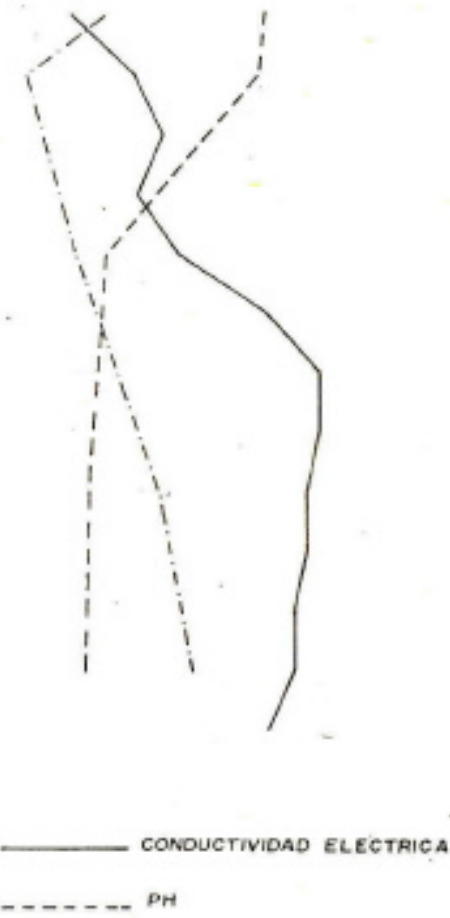

-....... TURBIDEZ

Variaciones de parámetros fisicos - químicos en relación a la profundidad en la cocha Carocurahuaite. Fecha 0406-87. Hora: 24:00 


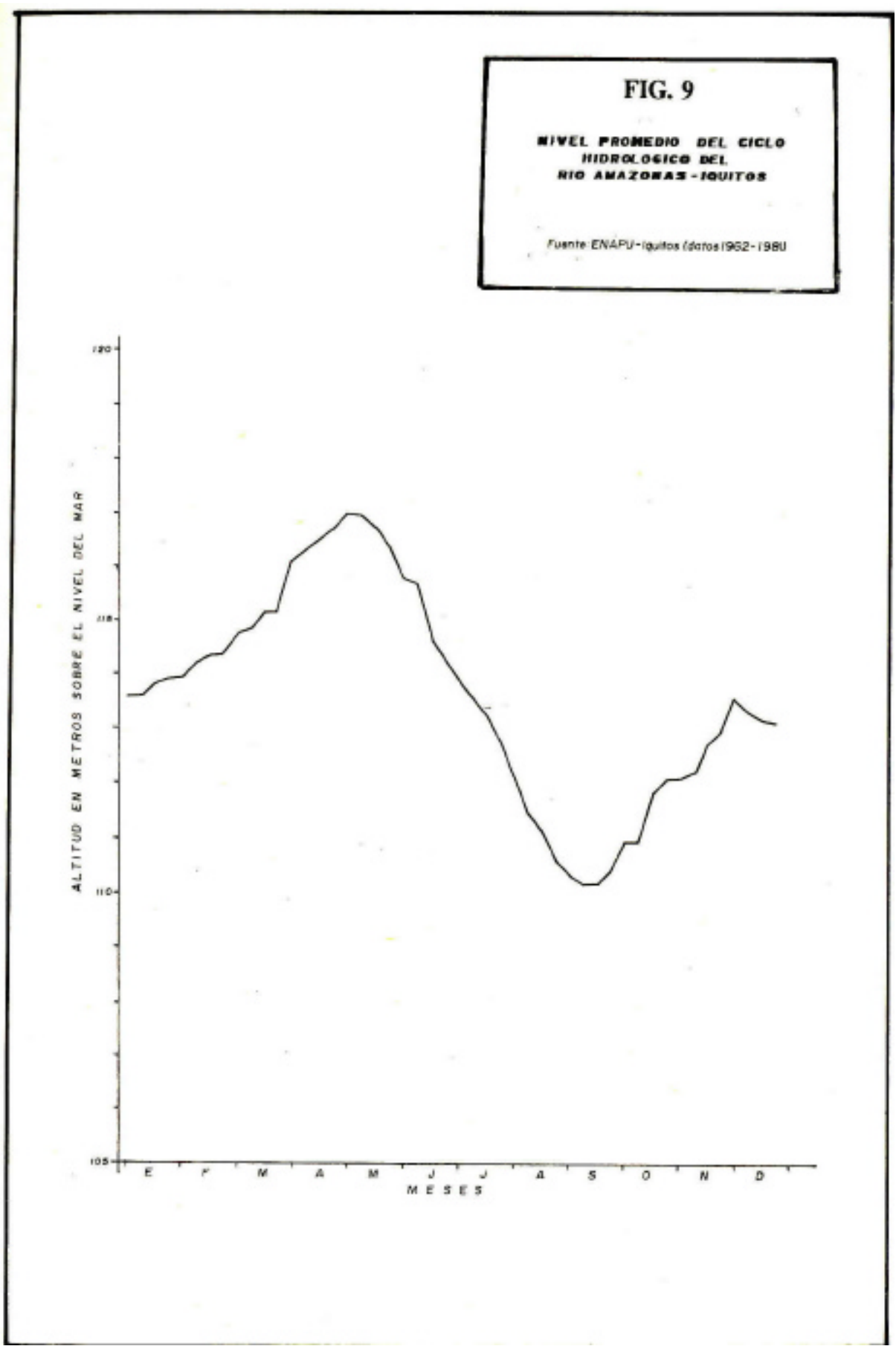


FIG. 10

CARACTERISTICAS EXTERNAS DEL CAMARON DEL RIO

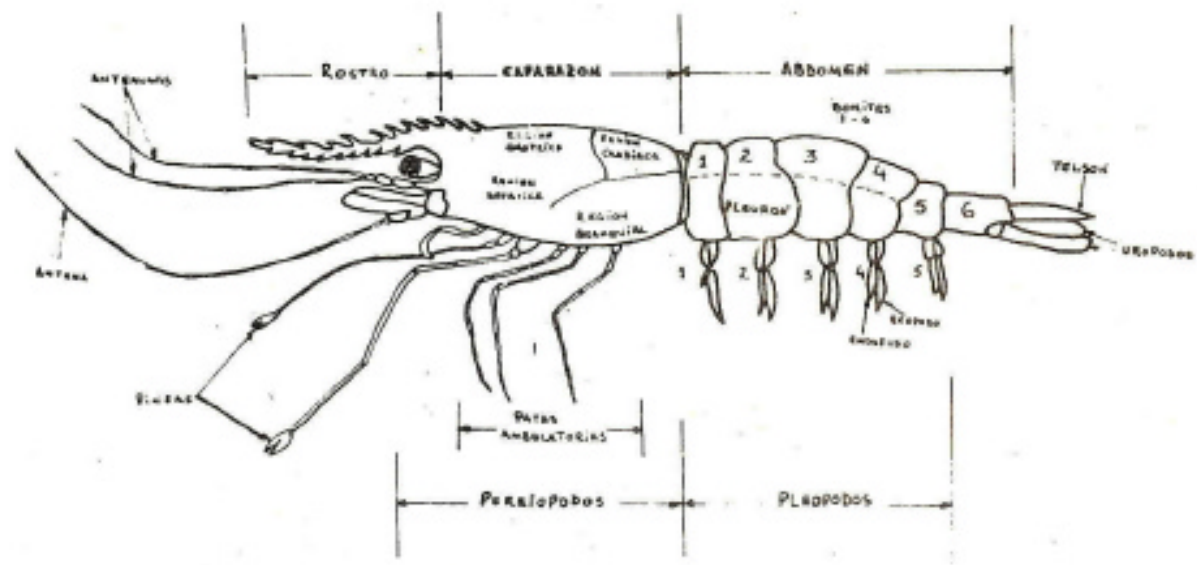

FIG. 11

DISTRIBUCION DE FRECUENCIAS DE LONGITUD EN

Macrobrachium amazonicum

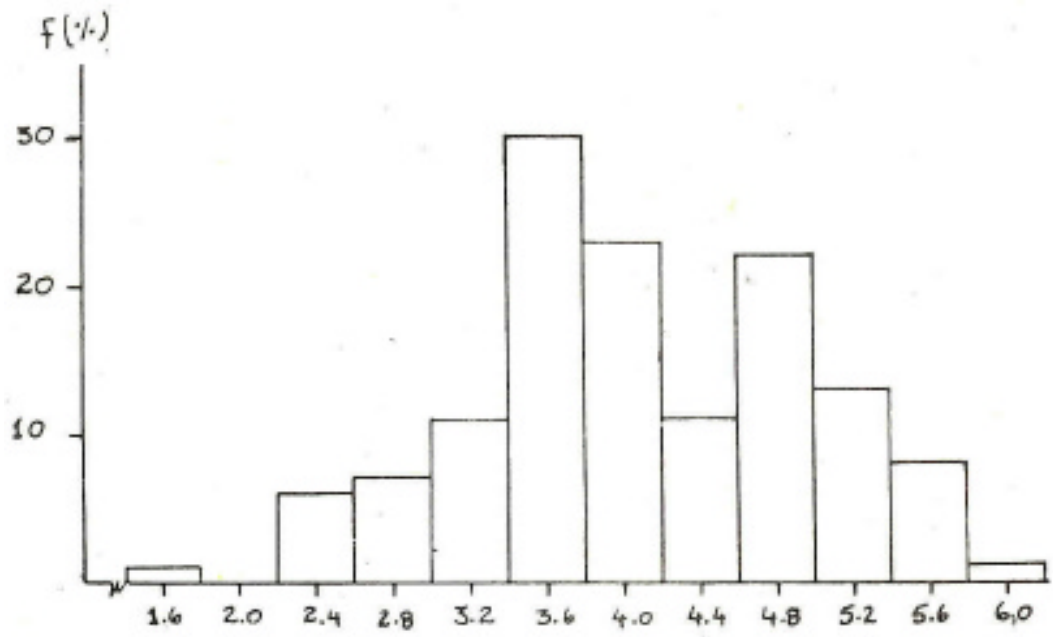




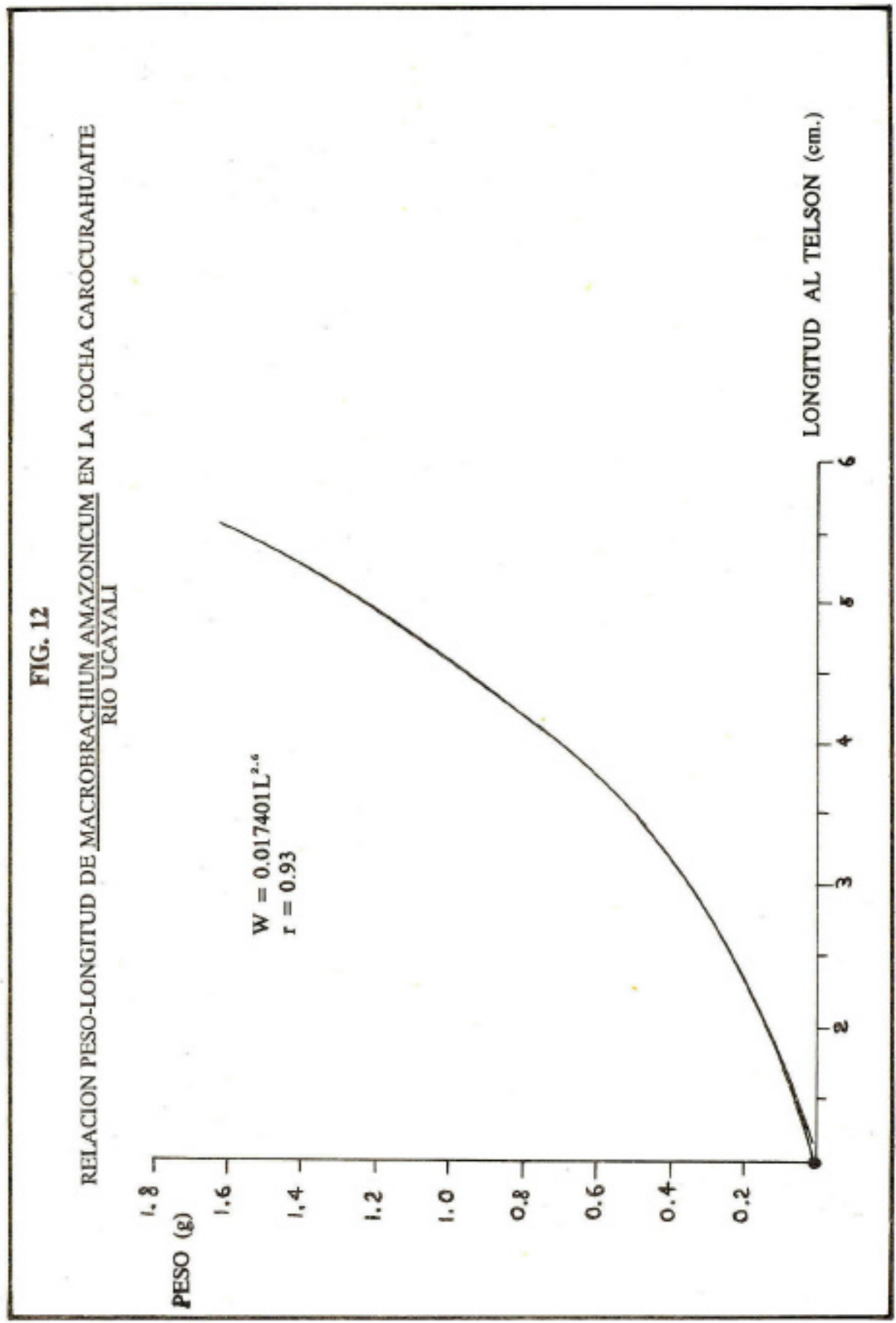




\section{FIG. 13}

DIFERENCIACION SEXUAL. Endópodo del segundo Pleópodo: (A) Fase Activa Masculina, (B) Fase Transicional, (C) Fase Femenina

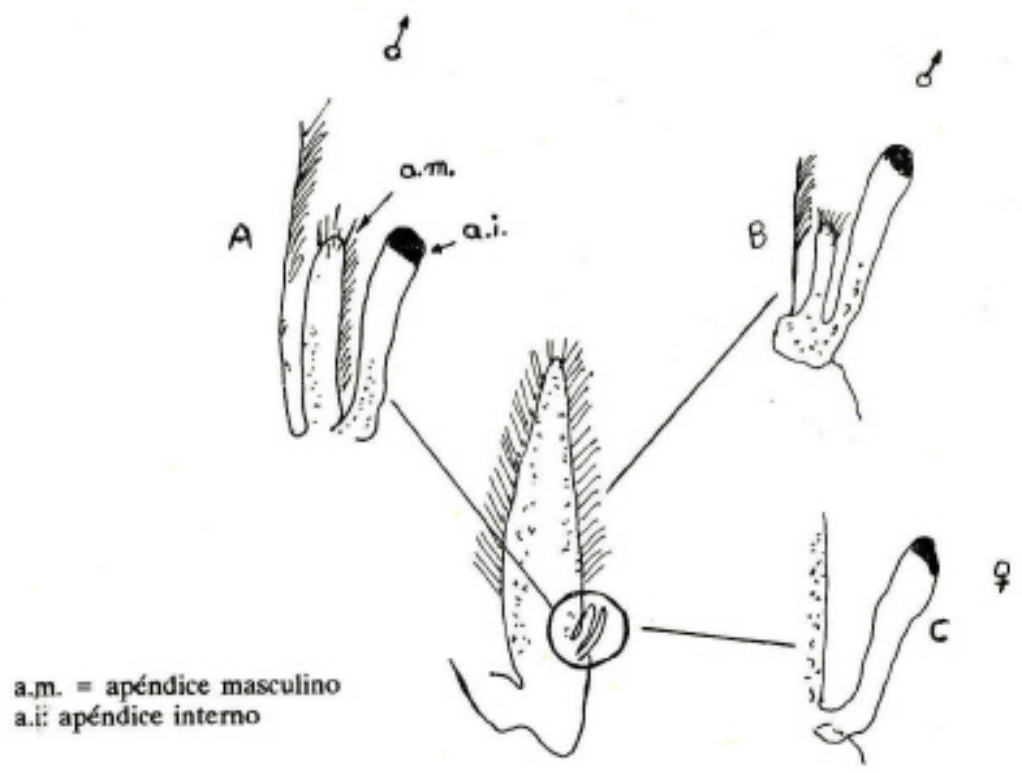

